\title{
Acquiring the notion of learning hypotheses in mathematics teacher education
}

\section{Aprendizaje de la noción de hipótesis de aprendizaje en la formación de profesores de matemáticas}

\author{
Pedro Gómez* \\ ORCID iD 0000-0001-9929-4675 \\ María C. Cañadas ${ }^{* *}$ \\ ORCID iD 0000-0001-5703-2335 \\ María A. Suavita*** \\ ORCID iD 0000-0001-9995-7723
}

\begin{abstract}
The notion of hypothetical learning trajectory has generated much interest among experts in mathematics education. It is proposed that this notion is a useful tool in teachers' teaching practice and that it is necessary to prepare teachers in their capacity to formulate hypothetical learning trajectories about specific mathematics school topics. It is therefore also necessary to explore the learning processes that teachers undergo when learning this notion in their education. In this article, we introduce the notion of learning hypotheses as an adaptation of the idea of hypothetical learning trajectory (SIMON, 1995). We describe how the groups of secondary-school mathematics teachers that participated in a teacher education program understood and used this notion in order to determine the contribution of a set of tasks to a learning goal previously established. We found that the groups developed their knowledge of the notion of learning hypotheses and used it in a heterogeneous way, and that the education program was partly successful in its goal to make the groups of teachers learn and perceive the notion's utility.
\end{abstract}

Keywords: Hypothetical learning trajectory. Teachers' expectations of students. Mathematics education. Teacher education. Teachers' learning.

\section{Resumen}

La noción de trayectoria hipotética de aprendizaje ha generado mucho interés entre expertos de Educación Matemática. Se afirma que esta noción es una herramienta útil para la práctica docente de los profesores y que es necesario formarlos en su capacidad para formular trayectorias hipotéticas de aprendizaje sobre temas específicos de las matemáticas escolares. Por tanto, es necesario explorar los procesos de aprendizaje de los profesores cuando aprenden esta noción. Este artículo introduce esta noción de hipótesis de aprendizaje como una adaptación de la idea de trayectoria hipotética de aprendizaje (SIMON, 1995). Describimos cómo los grupos de profesores de matemáticas de educación secundaria que participaron en un programa de formación de profesores entendieron y

\footnotetext{
* Doctor en Matemáticas, Universidad de Granada (UGR). Profesor visitante, Universidad de los Andes, Bogotá, Colombia. Dirección postal: Carrera 1, 18A-12, Bogotá, Colombia, CP: 111711. E-mail: argeifontes@ gmail.com. ** Doctora en Didáctica de la Matemática por la Universidad de Granada (UGR). Universidad de Granada, Granada, España. Dirección postal: Departamento Didáctica de la Matemática. Facultad de Ciencias de la Educación, Universidad de Granada, Campus de la Cartuja, s/n., Granada, España, CP: 18071. E-mail: mconsu@ugr.es.

*** Doctora en Educación por la Universidad Autónoma de Madrid (UAM). Universidad del Rosario, Bogotá, Colombia. Dirección postal: Calle 113 \# 55-78 (202), Bogotá, Colombia. E-mail: marian.suavita@ gmail.com.
} 
usaron esta noción para establecer la contribución de un conjunto de tareas a un objetivo de aprendizaje previamente establecido. Encontramos que los grupos desarrollaron su conocimiento de esta noción de una forma heterogénea y que el programa de formación fue exitoso parcialmente en su objetivo de hacer que los grupos de profesores aprendieran y percibieran la utilidad de esta noción.

Palabras clave: Aprendizaje de los profesores. Educación Matemática. Expectativas de los profesores sobre los estudiantes. Formación de profesores. Trayectoria hipotética de aprendizaje.

\section{Introduction}

In his seminal article, Simon (1995) defines the notion of hypothetical learning trajectory as a path by which learning can proceed. This path is directed by the learning goal and serves to guide instruction. Simon and Tzur (2004) identify three basic elements of a hypothetical learning trajectory: (a) learning goals, (b) tasks, and (c) learning hypotheses. Researchers have interpreted the notion in different ways. Some consider that the construction of hypothetical learning trajectories is the researcher's responsibility (CLEMENTS; SARAMA, 2004; LESH; YOON, 2004; STEFFE, 2004). Other authors stress that the hypothetical learning trajectories should be a tool for the teachers' planning (GRAVEMEIJER, 2004; SIMON; TZUR, 2004). Recent studies in teacher education confirm that introducing hypothetical learning trajectories improves teachers' abilities to take into account students' thinking (CLEMENTS et al., 2011), guides teachers' teaching decisions (WILSON, 2009), improves teachers' knowledge of mathematical content, provides better models of student-thinking, and facilitates the incorporation of these models into teaching (CORCORAN; MOSHER; ROGAT, 2009). These studies show that it is necessary to consider the hypothetical learning trajectory as a tool for teachers' practice (DARO; MOSHER; CORCORAN, 2011) and to research this tool's teaching and learning in mathematics teacher education programs (WILSON; SZTAJN; EDGINGTON, 2013).

This article develops within the framework of the research area presented above. It focuses on one basic element of a hypothetical learning trajectory: the teachers' hypotheses on how students can develop learning. We aim to describe how some groups of secondary school mathematics teachers understood and used this notion when, in the context of a teacher education program, they were asked to determine the contribution of a set of tasks related to a previously established learning goal. They were expected to use certain techniques, that we will explain below, to make hypotheses on how their students might approach the tasks: the possible strategies they could use and the mistakes they could make. As educators, we set up a list of actions that describe the steps the group of teachers could carry out in that situation. This list of 
actions allowed us to describe the performance of the groups of teachers in terms of what they did or did not accomplish within what was expected of them. Furthermore, based on the type of knowledge they could enact (that we explain in the next section), we established levels of development of their learning and determined the development level of each group. In what follows, we present the conceptual framework and research objectives. We then describe the method we used to tackle the research objectives, and present and interpret the results obtained. We end with some conclusions.

\section{Conceptual framework}

We describe the pedagogical concept of learning hypotheses, introduce the idea of teachers' actions, and present a model of pedagogical concepts learning.

\subsection{Learning hypotheses}

The notion of learning hypotheses is a pedagogical concept. Pedagogical concepts are conceptual and methodological tools that teachers use when enacting their knowledge. They can use them for producing specific information about a topic (for example, as we will show below, the learning paths of a task). Thus, pedagogical concepts are notions that support and give structure to teachers' professional knowledge. Some examples of the pedagogical concepts that we refer to are: learning hypotheses, learning goals, errors, conceptual structure, representation systems, resources, grouping, interaction or assessment strategies. In what follows, we describe the features of the learning hypotheses notion as a pedagogical concept that was used in the teacher education program in which we developed this study.

The pedagogical concept of learning hypotheses enables the teacher to establish predictions about how students' learning might develop when undertaking the tasks with which he aims to contribute to a specific learning goal. The teacher can expect students to enact certain task-solving strategies. Those strategies imply a sequence of steps that students perform to produce, from the information provided by the task, a solution to it. The learning hypotheses notion gives a concrete meaning to the idea of task-solving strategy. Students tackle the tasks through the activation of a series of capacities. A capacity is a basic mathematical knowledge or skill that can be shown in the observable behavior of a student when executing a routine task associated with a mathematics topic' (GÓMEZ; GONZÁLEZ; ROMERO, 2014). It represents a step that the student performs when solving the task. A capacity has a level of precision that 
depends on the educational level: it represents a routine procedure appropriate for students at that educational level.

The teacher can establish his predictions about the possible students' task-solving strategy actions by means of the capacities sequences that he thinks the students, having the knowledge and skills to employ it, can activate to tackle a task. These capacities sequences are called learning paths (GÓMEZ; GONZÁLEZ; ROMERO, 2013, p. 178). A learning path is valid for a task if the activation of its capacities sequence solves such task. Since students can tackle a task in different and valid ways, a task can be associated with more than one learning path. Furthermore, achieving a learning goal usually requires being able to solve more than one task. Each task might aim at particular aspects (cognitive demands) of the learning goal (CHICK, 2007). The set of learning paths for the tasks related to a learning goal can be represented in a diagram. The learning paths' diagram characterizes the learning goal in terms of the capacities sequences the student is expected to be able to activate in tackling tasks related to the topic. What should a teacher know and be able to do to use the notion of learning hypotheses for producing the learning paths' diagram for the learning goal and determine how a task contribute to that learning goal?

\subsection{Teachers actions}

Teachers take actions in all phases of their teaching (planning, implementing, and evaluating). We assume Schoenfeld's (2000) idea of action as an element of action sequence. We also adapt this idea to the planning process in a teacher education program in which the groups of teachers were asked, based on the procedure described above, to envision how students might perform when facing a task. In other words, they were asked to put into play the learning hypotheses notion. The teacher education program educators expected them to perform certain actions. We focus on those fine-grained actions that are observable and can be recognized in their written productions (RINK, 1993; GÓMEZ; GONZÁLEZ; ROMERO, 2013; GÓMEZ; GONZÁLEZ; ROMERO, 2014). For example, 'After performing the learning paths' analysis to propose reasons for arguing the tasks contribution to the learning goal is one action corresponding to the pedagogical concept learning hypotheses. A document produced by a group of teachers can evidence whether they executed the action and whether they did it as expected by the educators.

We constructed a list of actions that break down the educators' learning and performance expectations for a task that requires teachers to (a) identify a set of tasks associated 
with the learning goal, (b) establish the learning paths for each task, (c) represent the set of learning paths, (d) use the information to characterize the contribution of the set of tasks to achieve the learning goal, considering the difficulties and errors foreseen, and (e) review the entire process to reformulate the capacities and tasks in order to improve the learning goal characterization. For example, for depicting the set of learning paths, we identified two actions, among others: (a) representing the learning paths using a diagram, and (b) indicating the reiteration of capacities. The list of actions for the whole task can be found in https://goo.gl/rQnhYS. We organized the actions in this list according to the theoretical, technical, or practical knowledge of the pedagogical concept learning hypotheses that we explain in the next section.

\subsection{Acquiring a pedagogical concept. The TTPK model}

In order to plan lessons on a school mathematics topic, teachers should know it from multiple perspectives (SHULMAN, 1986; COONEY, 2004, p. 511). This knowledge is topicspecific. It involves, for instance, knowledge of pedagogical concepts for selecting concepts and procedures, representation systems and phenomena related to the topic; establishing the learning goals that teachers expects from the students; foreseeing the students' learning-including the errors that they might encounter when learning the topic; and establishing the teaching (e.g. tasks, resources, grouping, interaction) and assessment strategies that are more appropriate for developing the learning expectations identified (e.g. instruments and procedures for collecting and analyzing the students' performance). Teachers can enact their knowledge of such pedagogical concepts for analyzing the topic to produce information that can support their planning choices (CHICK, 2007; CHARALAMBOUS, 2008; CLARKE; ROCHE, 2010). As Simon (2008) has argued, there is a need for learning and teaching studies of specific pedagogical concepts in teacher education programs.

The TTPK model can be used for understanding how learning takes place in mathematics teacher education programs, which expect teachers to learn and use pedagogical concepts to become competent in lesson planning (GONZÁLEZ; GÓMEZ, 2014). This model was inspired by the Aristotelian categories of episteme, techne, and phronesis (ARISTOTLE, 350 BC/1994), which have been adopted and adapted by several authors for referring to teachers' knowledge and performance and for exploring the duality between theory and practice in teacher education (ORTON, 1997; BACK, 2002; SAUGSTAD, 2005). It involves three types of knowledge: theoretical, technical, and practical knowledge. 
The theoretical knowledge of a pedagogical concept emerges from the knowledge base for teaching and refers to the theoretical option that the educators of the teacher education program have chosen among the multiple existing meanings in the pedagogical research knowledge base. Hence, this knowledge is program-specific. It is usually presented in terms of other concepts and the relationships among them. We call these concepts the key ideas that characterize the pedagogical concept's theoretical knowledge.

In order to produce information on a topic, related to a pedagogical concept, the teacher operationalizes into techniques the key ideas that characterize the pedagogical concept's theoretical knowledge. Those techniques should satisfy two conditions: (a) to be grounded on the pedagogical concept's theoretical knowledge and (b) to make possible to produce information about the topic that can be used for planning purposes. Hence, technical knowledge is program and concept-specific. Among all techniques that satisfy these two conditions, educators propose and make explicit, in the teacher education program, those that they consider most effective for planning purposes.

The teacher can use the information that emerges from a pedagogical concept's technical knowledge for planning purposes. The pedagogical concept's practical knowledge refers to the set of techniques involved in such process. These techniques should satisfy two conditions: (a) to use the information that emerges from the pedagogical concept's technical knowledge and (b) to involve decisions about the planning process. Among all the possible techniques, educators propose and make explicit those that they consider most effective and better suited to each scope and purpose.

Learning goal, capacity, capacities sequence, learning path, and diagram are the key ideas that form the pedagogical concept's theoretical knowledge for the learning hypotheses. The concept's technical knowledge is based on the techniques to produce the learning paths of a task and the diagram of a learning goal. The pedagogical concept's practical knowledge refers to the techniques that, for example, permit the reformulation of the capacities and tasks from the information that emerges from their learning paths and from the learning goal's diagram.

\section{An example}

We illustrate some of the ideas of the conceptual framework with an example from the work of Bernal et al. (2014), who designed a didactic unit on systems of linear equations with two unknowns. This example refers to the work they did as one of the groups that participated in the teacher education program in which we performed this study. It depicts what they did for 
characterizing a learning goal in terms of capacities and learning paths. The learning goal in this example was "To apply the graphing method to obtain points of intersection between lines and the solution of systems of linear equations with two unknowns". The group proposed a sequence of tasks for this goal. The first task was the following one.

The two lines obtained by representing graphically the two equations of a system intersect at the point $(1,-2)$. Can $x+2 y=15$ be one of the equations in the system? Verify graphically.

These authors analyzed this task and the others in the set, and, based on the notion of learning hypotheses, proposed several learning paths for each task. For that purpose, they had previously analyzed the concepts and procedures involved in the mathematical topic. Then, they tried to solve each task as if they were students. They recorded each step (capacity) performed by writing them out. They organized those steps into the different task-solving strategies (learning paths). The capacities are identified with the letter $\mathrm{C}$ and a number. The full list of capacities proposed by this group may be found at http://cl.ly/1W0z1M0Y371J. We show two of the learning paths that they identified in the following lines.

(1) Substituting numerical values in linear equations (C8), verifying that the solution satisfies the linear system equations (C9), isolating unknowns in one equation (C2), developing and interpreting tables of values (C23), and representing lines on a plane from two or more points $(\mathrm{C} 12)$. We use the following notation to summarize this learning path: $C 8 \rightarrow C 9 \rightarrow C 2 \rightarrow C 23 \rightarrow C 12$.

(2) On the Cartesian coordinate plane, locate the solution set of a system of linear equations (C19), isolate unknowns in one equation (C2), represent affine linear functions on the Cartesian coordinate plane from the parameters identified in the equation (C14), and verify that the solution satisfies the equations in the linear system (C9). This sequence of capacities corresponds to the learning path $C 19 \rightarrow C 2 \rightarrow C 14 \rightarrow C 9$.

Figure 1 presents the diagram developed by Bernal et al. (2014) for the learning goal in question. The diagram contains the learning paths that the group identified for the tasks they were proposed and, therefore, collects the information concerning their expectations about how the students might progress in their learning. In this figure, the numbers in blue indicate the number of times that the capacity is activated, the numbers within the arrows indicate the connection frequency between two capacities, and the numbers in red and green represent the frequency with which the capacity was the beginning or the end of a learning path. 


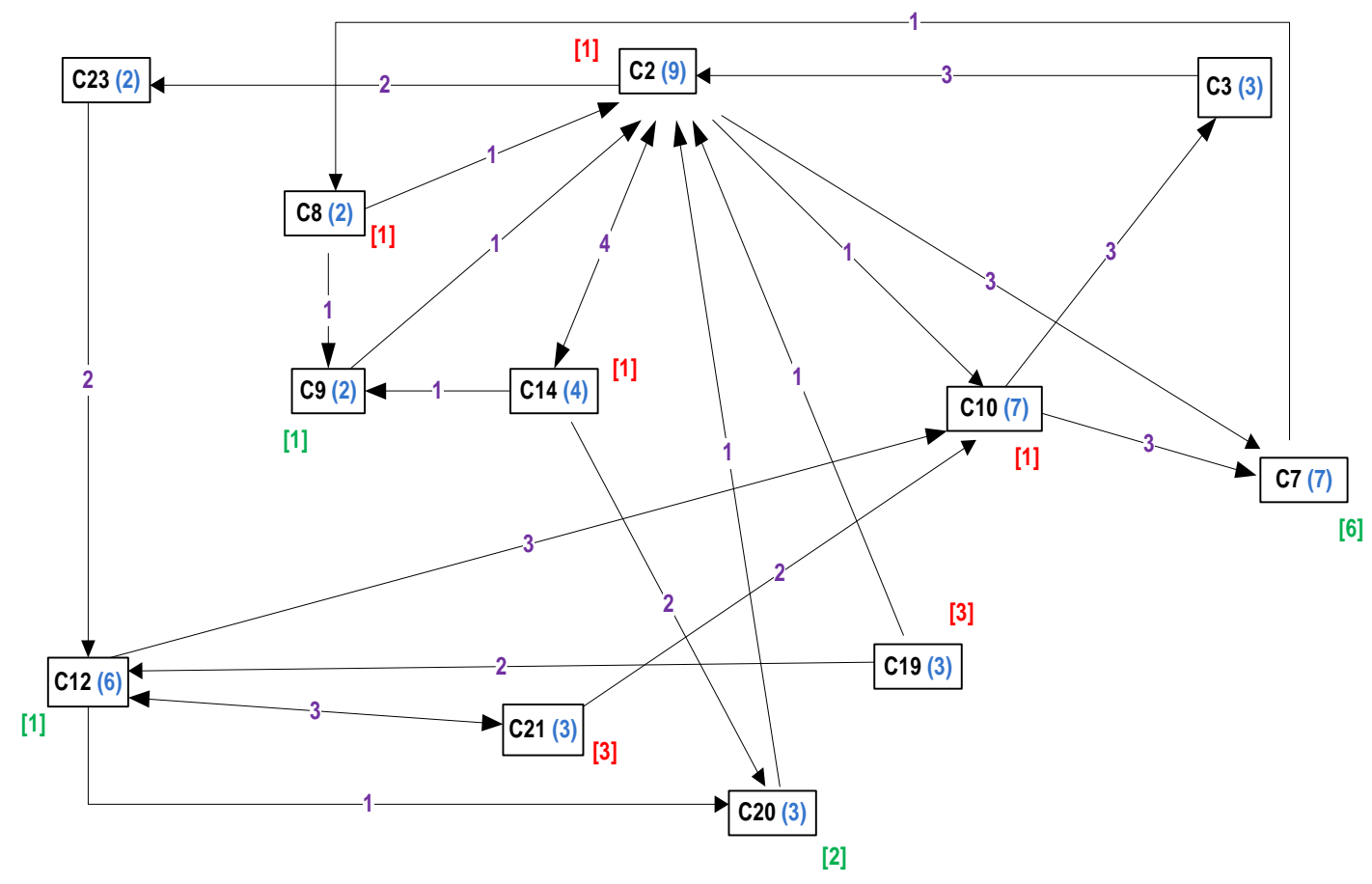

Figure 1 - Diagram for learning goal Source: BERNAL et al. (2014).

When producing this diagram, the group enacted several of the actions that we, as educators, expected them to do. For instance, they proposed tasks related to the learning goal, produced a list of capacities and learning paths for all the tasks; represented them with a diagram; and denoted the capacities that are more often used in the learning paths.

The analysis of a learning goal diagram, as the one in Figure 1, enables teachers to (a) show, based on the capacities activated, whether the tasks proposed contribute to the learning goal characterization; and, from this information, (b) modify the tasks so that they better contribute to the learning goal. Modifying the tasks can give rise to revision of the capacities that students can activate to tackle them. The list of teachers' actions includes those actions that the teachers are expected to perform when analyzing a learning goal diagram.

\section{Focus of the study}

The goal of this study is to describe and characterize the pedagogical concept learning for the learning hypotheses by groups of teachers that, in a teacher education program, carried out a task involving that pedagogical concept. We put the TTPK learning model into action, and we use the notion of teacher action as a mean of collecting and coding data representing the teachers' learning processes. We seek to (a) describe the performance of the groups of teachers in terms of the actions that they performed and (b) based of their performance, establish 
development levels for their learning according to the three types of knowledge proposed by the TTPK model.

\section{Method}

In this section, we describe the teacher education program and establish the information sources for the study, the data coding procedure, and the procedures for analyzing the information that emerged from coding the data.

\subsection{Education context and participating teachers}

The program was organized around eight consecutive modules that involved the analysis of a school mathematics topic, the production of a curriculum design for this topic, its implementation in the classroom, information gathering on the implementation, the analysis of this information, the evaluation of the design and implementation, and the production of a new version of the curriculum design. Teachers were organized in groups of 4 people and each group worked on 32 tasks during the two-year long program. The tasks were grouped in 8 modules (4 tasks each).

Each group of teachers had one mentor during the whole program. All mentors had a degree in Mathematics, a PhD in Mathematics Education, and had experience in training mathematics teachers. Mentors were in charge of commenting their group's draft for each task. Each module had an educator in charge, who introduced the module's subject and assessed the groups' performance during the module. For each task, the groups worked virtually and met face-to-face at the end of the first week of work in such task. The local program coordinator supported this face-to-face work. Teachers could interact virtually with their mentor or the educator at any time.

The whole group under study was composed by 26 in-service mathematics teachers. Most of them held bachelor's degrees in mathematics and physics or in mathematics, and around one fifth of them held bachelor's degrees in primary education with a focus in mathematics. All of them were working as teachers in secondary education in public or private schools in Colombia, teaching students between 13 and 17 years of age. There were six groups of teachers. The groups worked on the following school mathematics topics: whole numbers addition and subtraction, linear equations with one unknown (two groups), graphing methods for solving linear equations systems with two unknowns, and trigonometric ratios (two groups). 


\subsection{Instruction and information sources}

In what follows, we refer specifically to the module on cognition and to the task on that module's learning hypotheses from which we obtained the information coded and analyzed. The educator responsible for this module introduced the theoretical aspects of the learning hypotheses concept during the first week of the module. She also presented some examples of the techniques for producing and analyzing the learning paths diagram of a learning goal. Most of this information was also available in the educator's notes, which were available to the groups of teachers. As we explain in detail below, the six groups produced a draft and a final document with their task solution for their specific school mathematics topic. These documents represent the information sources for this study.

This study is focused on the task concerning the learning hypotheses pedagogical concept. This task belongs to the third module. Before addressing this task, the groups had established learning goals for their topic and identified the mistakes students could make on it. Each group selected one learning goal. As mentioned before, this task required the group of teachers to (a) identify a set of tasks associated with the learning goal, (b) establish the learning paths for each task, (c) represent the set of learning paths, (d) use that information to characterize the contribution of the set of tasks to achieve the learning goal, considering the difficulties and errors foreseen, and (e) review the entire process to reformulate the capacities and tasks in order to improve the learning goal characterization.

The groups of teachers had two weeks to accomplish the task. At the end of the first week, each group submitted a draft of their work. Their mentor commented on this draft. Each group met virtually and at the university after receiving the mentor's comments. At the end of the second week, based on the mentor's comments and their effort for improving their work, the group submitted a final document of this activity and presented it to the educator in charge of the module, to some of the mentors and their peers.

In what follows, we present a fragment of the work related to the first part of the activity done by the group that worked on systems of linear equations with two unknowns that we mentioned before. It refers to the learning goal learning hypotheses 'Applying the graphical method to obtain the solution of linear equations systems with two unknowns considering the precision the tackled situations require'. In Figure 1, we showed the learning paths diagram of the learning goal that Bernal et al. (2014) proposed in their draft in which they reached the following conclusions through the diagram analysis. 
The capacity $\mathrm{C} 2$ predominates since the information given in the statements appears in two of the tasks in canonical equations and, to identify the line parameters (C10), the student should express it in standard form (C7) and approach it with its respective diagram $(\mathrm{C} 14)$... We see that the capacities used most often as a starting point in the learning paths (C19 and $\mathrm{C} 21)$ are directly related to diagram-type procedures. The capacities that end these paths are proof of the understanding and application of the graphing method to solve non-routine problems. In conclusion, the problems revolve around the student's parameters manipulation and their graphic and algebraic representation in scientific situations characteristic of mathematics (p. 4-5).

The following is an example of two comments made by this group's mentor to the draft they proposed.

When I try to solve the task, I get different learning paths. For example, C12 or C14 C19 - C20 - C25 are possible learning paths for task 2.

... I suggest adding a capacity concerning the coherence matching between the results in different representation systems.

As expected in the program methodology, the group improved its work on this basis and on the other mentor's comments, and sent the final version of its document at the end of the second week. As it was usually the case, the mentor's comments motivated the group to make changes in their previous work. For example, the group proposed a new task, which consisted of representing lines $3 x \quad 2 y=0, y+\frac{1}{2} x=4$, and $y=\frac{1}{2} x \quad 2$, and determining the vertices of the triangle formed. Further, the group identified the capacities that they had to rewrite; reformulated questions in the task so that it could enact more capacities; and constructed new questions for enacting capacities that were enacted before the reformulation. The group also explained the need to reformulate the task to relate it more closely to the learning goal and to contribute to overcoming the mistakes that the student could make. After this process, they reformulated the tasks as follows: Graph the lines $3 x \quad 2 y=0, y+\frac{1}{2} x=4$, and $y=\frac{1}{2} x \quad 2$ on the plane. What figure do they form? Why do they form this figure? What are the points coordinates at which the lines intersect?

Our information sources were the drafts and final documents of the six groups on the learning hypotheses task.

\subsection{Data coding and analysis}

We based the coding of the groups' documents on the notion of action and used the list of actions mentioned above (https://goo.gl/rQnhYS). For each action, we recorded whether the groups executed the action and whether they did so, as expected by the educators. Our purpose is to describe the groups' learning based on this information. We analyzed and summarized the 
performance of the teachers' groups of teachers for each action. On the other hand, for each type of knowledge proposed by the TTPK model and based on the groups' performance on the actions pertaining to each type of knowledge, we defined some indicators and "development levels" for each indicator. We situated each group on one of those levels. We explain the idea of indicator and development levels in section 7.

\section{Groups' actions}

We describe the groups' learning from two sources: summarizing the groups' performance (based on their actions) and distinguishing, in terms of development levels, the groups' performance on each knowledge type. In this section, we characterize the groups' performance based on the analysis of the actions performed. We organized the groups' performance around the three ideas that structured the task: (a) learning paths and capacities precision, (b) learning paths' diagrams, and (c) tasks contribution and reformulation.

\subsection{Learning paths and capacities precision}

Two features of the learning paths proposed by the groups stood out in the groups' performance: the capacities precision and learning paths proportion that solve the task. Capacities can be formulated with different levels of precision and learning paths might represent or not a solution to a task. As mentioned before, a capacity has a precision level appropriate to an educational level when it represents a routine procedure appropriate for students at that educational level. In Table 1 we present the groups' performance on these issues: it presents the groups with the highest and lowest percentage in both aspects. They are ordered from higher to lower percentages. The percentages in this table represent the capacities proportion used by a group that had the appropriate precision level and learning paths proportion that solved the task.

Table 1 - Capacities precision and learning paths proportion that solve the task

\begin{tabular}{ccc}
\hline Group & $\begin{array}{c}\text { Precision of } \\
\text { capacities (\%) }\end{array}$ & $\begin{array}{c}\text { Proportion of learning paths that solve } \\
\text { the task (\%) }\end{array}$ \\
\hline 6 & 100 & 86 \\
1 & 100 & 80 \\
2 & 100 & 64 \\
5 & 97 & 57 \\
4 & 96 & 50 \\
3 & 90 & 43 \\
\hline
\end{tabular}

Source: Research Data 
As can be seen in Table 1, the groups with $100 \%$ of precise capacities showed a higher learning paths proportion that solved the task. In contrast, groups with lower capacities proportion with the appropriate precision showed a lower learning paths proportion that solved the task. We thus observe a relationship between capacities precision and the learning paths that the groups proposed to solve the tasks. We performed a correlation analysis and established that these two variables are correlated at a high-significance level, $\mathrm{p}=0.05$.

\subsection{Diagram}

All but one of the groups constructed the learning paths according to the technique presented in the textbook. The sixth group did not make explicit any of the actions for constructing the diagram representation. We have evidence, however, that this group did produce the diagram but did not include it in the final document. Only two groups had difficulties in constructing the diagram and made minor errors: (a) omitting one task, and (b) miscounting the capacities.

One group produced a learning paths' diagram correctly but did not interpret it and thus did not perform most of the actions required for analysis or argumentation. Two groups tried to justify the contribution of their tasks reformulation to achieving the learning goal and overcoming errors but did so only in relation to the learning goal.

Two groups stood out for adding capacities (from the draft to the final document) in higher proportion $(60 \%$ and $28 \%)$ than the other three $(8 \%, 9 \%$, and $14 \%)$. Only one group did not add capacities. The group that obtained the highest proportion in adding capacities also had a low number of capacities in its initial list. Half of the groups justified the inclusion of new capacities. Of the six groups, five eliminated capacities.

\subsection{Contribution and reformulation of the tasks}

The groups partially established the tasks contribution to the learning goal proposed. In fact, only two groups justified the tasks contribution to the learning goal proposed, and only one group justified the reiteration of capacities sequences in terms of the difficulties foreseen. All the groups identified the capacities that appeared frequently in the learning paths, but none of the groups analyzed this reiteration and its relation to the learning goal.

All but one group identified capacities that did not contribute significantly to the learning goal. Only one group, however, argued the capacities contribution to the learning goal. 
When reformulating the tasks (from the draft to the final document), one group added questions, another group reformulated questions, and two groups reformulated and added questions. The remaining two groups did not perform either of these actions, as they expressed difficulties in reformulating tasks based on the diagram information. Two groups did not reformulate the tasks: one did not interpret the diagram information, and the other did not produce the diagram.

\subsection{Summary of groups' performance}

We see heterogeneity in the learning paths proportions proposed to solve the tasks and in the tasks proportion to be resolved by all the learning paths. These results are explained at least in part when we consider the capacities precision that the groups proposed: the higher the proportion of precise capacities, the greater the learning paths proportion that solved the tasks. This result shows the relationship between the theoretical knowledge developed by the groups (importance of the capacities precision) and the development of their technical knowledge (validity of the learning paths proposed). The groups that confirmed the importance of specifying the capacities as an element of the pedagogical concept's theoretical knowledge were able to put the notion into practice efficiently in producing valid learning paths (paths that solve the task). In general, the groups managed to develop the techniques correctly to produce the learning paths diagrams. However, the groups put the practical knowledge of this information into play partially. Some groups did not use the information from the diagram to reformulate the capacities. For other groups, the results show only partial and heterogeneous use of the diagram information to analyze the tasks' contribution to the learning goal with the detail and justification expected. We will now develop these results in greater depth by analyzing the development levels of the indicators that emerged from the data.

\section{Development levels}

With the performance description for all the groups as background, we wanted to characterize the groups' learning for each knowledge type. For distinguishing the groups' performance, we identified, among all the actions common to all the groups, those that presented differences between groups. For example, the action 'propose learning paths for all the tasks' was not considered because all the groups proposed learning paths for all the tasks and, therefore, there were not differences among the groups for this action. We constructed indicators, on 
each knowledge type, for the sets of one or more related actions for which the groups presented differences. Therefore, the indicators emerged from the data: they are sets of actions that allowed us to distinguish groups' performance. For each indicator, we defined development levels, in such a way that the groups' performance for that indicator could be distinguished.

For example, 'diagram construction technique' was an indicator. We established this indicator based on the number of groups that performed the seven actions concerning the diagram: (a) representing using a diagram, (b) indicating the number of times that capacities are connected, (c) noting the reiteration of capacities, (d) indicating the capacity that is at the beginning of a learning path, (e) noting the number of times that a capacities sequence is used, (f) indicating the number of times that the capacity is the origin, and (g) if there are capacities nonused, they are shown. We defined the development levels of this indicator from the data itself as follows:

- if one group performed one or two of those actions, we assigned it to the Weak level;

- if it performed three or four actions to the Medium level;

- and if it performed five to seven actions to the Advanced level. We followed the same procedure for all the indicators: their development levels emerged from the evidence in such way that they enabled us to distinguish the groups' performance on the indicator. Hence, other groups' data might imply other development levels.

We classified the indicators according to the knowledge type to which they corresponded, as shown in Table 2.

Table 2 - Indicators by knowledge type for development levels

\begin{tabular}{ll}
\hline Type of knowledge & \multicolumn{1}{c}{ Indicator } \\
\hline Theoretical & $\begin{array}{l}\text { Proportion of learning paths that solve the task } \\
\text { Capacities precision }\end{array}$ \\
Technical & Graph construction technique \\
Practical & Reformulation of tasks \\
\hline & Source: Research Data
\end{tabular}

Table 3 presents the criteria for establishing the development levels for the indicators pertaining to the theoretical knowledge. According to the data, the percentages included in this table enable us to distinguish the groups' performance on those indicators.

Table 3 - Levels of development of theoretical knowledge

\begin{tabular}{lcc}
\hline $\begin{array}{c}\text { Level of } \\
\text { development }\end{array}$ & $\begin{array}{c}\text { Proportion of learning paths } \\
\text { that solve the task }\end{array}$ & Capacities precision \\
\hline Weak & Under $50 \%$ & $90 \%$ or less \\
Medium & $50 \%$ to $80 \%$ & Over $90 \%$ and less than $100 \%$ \\
Advanced & Over $80 \%$ & $100 \%$ \\
\hline
\end{tabular}

Source: Research Data 
We described above the indicator 'diagram construction technique'. This is the indicator for technical knowledge. We summarize the criteria for the development levels for this indicator in Table 4.

Table 4 - Levels of development of technical knowledge

\begin{tabular}{lc}
\hline \multicolumn{1}{c}{ Level of development } & Number of actions performed \\
\hline Weak & Fewer than 3 \\
Medium & 3 or 4 \\
Advanced & More than 4 \\
\hline
\end{tabular}

Source: Research Data

In reformulating and analyzing the tasks, a group could perform three actions: (a) add new questions, (b) add capacities, and (c) eliminate capacities. We established the development levels for this practical knowledge indicator as shown in Table 5.

Table 5 - Levels of development of practical knowledge

\begin{tabular}{lc}
\hline \multicolumn{1}{c}{ Level of development } & Number of actions performed \\
\hline Weak & Fewer than 2 \\
Medium & 2 \\
Advanced & More than 2 \\
\hline
\end{tabular}

Source: Research Data

With the above indicators and their corresponding development levels, we were able to organize the data and produce the results summarized in Table 6. These results complement and refine the analysis results for the actions presented in the previous section. The groups appear in the table rows. The columns are organized by the knowledge type, each with its three development levels. For example, Group 2 is located on the medium development level for the criterion of theoretical knowledge of the learning path notion (Plp) but on the advanced development level for theoretical knowledge in capacities precision $(\mathrm{Pc})$. This means that $50 \%-80 \%$ of this group's learning paths solved the tasks, and $100 \%$ of the capacities proposed were precise.

Table 6 - Classification of groups into development levels

\begin{tabular}{|c|c|c|c|c|c|c|c|c|c|}
\hline \multirow[b]{2}{*}{$\mathrm{Gr}$} & \multicolumn{3}{|c|}{ Theoretical knowledge } & \multicolumn{3}{|c|}{$\begin{array}{r}\text { Technical } \\
\text { knowledge }\end{array}$} & \multicolumn{3}{|c|}{$\begin{array}{c}\text { Practical } \\
\text { knowledge }\end{array}$} \\
\hline & $\mathrm{W}$ & $\mathrm{M}$ & A & $\mathrm{W}$ & $\mathrm{M}$ & $\mathrm{A}$ & $\mathrm{W}$ & $\mathrm{M}$ & A \\
\hline 1 & & & Plp-Pc & & & & & & \\
\hline 2 & & Plp & Pc & & & & & & \\
\hline 3 & Plp-Pc & & & & & & & & \\
\hline 4 & Plp & $\mathrm{Pc}$ & & & & & & & \\
\hline 5 & & Plp-Pc & & & & & & & \\
\hline 6 & & & Plp-Pc & & & & & & \\
\hline
\end{tabular}


The results in Table 6 allow us to describe the work of each group in terms of the TTPK model, presenting the groups according to their development levels for the three knowledge types. From the theoretical knowledge perspective, one group is at the Advanced level, one at the Medium level, and two at the Weak level. Of the other two groups, one is between the Advanced and Medium levels, and the other between the Medium and Weak levels. In terms of technical knowledge, two groups are at the Advanced level, two at Medium level, and two at Weak level. For practical knowledge, two groups are at the Advanced level, three at Medium level, and one at Weak level.

We see that not all the groups are at the same development level for all knowledge types. There is some homogeneity, however, in a group's development level regarding the three knowledge types. The two groups (1 and 6) that are at the Weak level in theoretical knowledge are also at the Weak level in technical knowledge. One of these is also at the Weak level for practical knowledge, whereas the other is at the Medium level. The groups that are at the Advanced or Medium level for theoretical knowledge are also at these levels for technical and practical knowledge. Group 3 is distinctive because it shows an Advanced development level for technical and practical knowledge but is at the Medium level for theoretical knowledge.

\section{Discussion}

The notion of hypothetical learning trajectory has generated much interest among experts in mathematics education: It is believed to be a useful tool for the teacher's teaching practice. In this article, we have investigated teachers' learning processes of this notion in a teacher education program. We have described the learning of groups of mathematics teachers of the learning hypotheses notion. This paper contributes to the research being performed on the hypothetical learning trajectories notion as a tool for the teacher in the sense indicated by Daro, Mosher and Corcoran (2011).

In spite that some researchers considering that teachers are not supposed to construct hypothetical learning trajectories (CLEMENTS; SARAMA, 2004; LESH; YOON, 2004; STEFFE, 2004), this study shows that teachers can tackle this kind of task. Based on the learning hypotheses notion, the teachers' groups that participated in this study were able to characterize a learning goal and establish how a set of tasks might contribute to it. On doing so, they were able to account for how students might think and act when solving tasks (CLEMENTS et al., 2011) and analyze that information in order to improve their planning (CHICK, 2007; CHARALAMBOUS, 2008; WILSON, 2009; CLARKE; ROCHE, 2010). As we mentioned above, constructing a learning paths' diagram for a learning goal requires teachers to delve into 
the mathematical content of the topic at hand. In this sense, the learning hypotheses notion promotes teachers' knowledge development for the subject matter, as suggested by Corcoran, Mosher and Rogat (2009). Even though some groups did not accomplish the task with full success, other groups were able to perform close to what was expected. This means that the learning hypotheses notion is accessible to teachers as a tool for their practice (DARO; MOSHER; CORCORAN, 2011). Nevertheless, as our results show, and we reflect at the end of this section, teachers had difficulties grasping all the notion complexity and the techniques implied in it. This means that, as suggested by Wilson; Sztajn and Edgington (2013), more research is needed on how to include the notion in teacher education programs so that it becomes useful for teachers' practice. Our study has identified some aspects of the notion that have to be considered.

Constructing the list of actions concerning learning hypotheses - for describing the specific activities that the teachers were expected to perform while working on the learning hypotheses - is one of the contributions of this article. The actions permitted us both to describe the work that the teachers' groups performed relative to the learning hypotheses and to compare the work of the different teachers' groups involved in the program. These differences enabled us to establish development levels for acquiring the learning hypotheses based on the three knowledge types considered in the TTPK model.

We classify the results into three categories: (a) relation between the key ideas of the learning hypotheses notion; (b) perception of the notion utility by the teachers being prepared; and (c) development of the three knowledge types proposed by the TTPK model.

One feature that distinguishes the quality of a learning path is whether the activation of its capacities sequence results in the solution of a task. A learning path that does not comply with this condition does not serve its purpose. We have found that the quality of the learning paths proposed by the teachers' groups depends on the capacities precision they propose. We wish to stress two aspects of this result. On the one hand, it is surprising that experienced teachers propose processes for solving a task that do not really solve it. This situation can be explained, at least partially, by the fact that the program requires them to explain the task-solving strategy with the help of the capacity notion, which is new for them. This study shows that, if the teachers do not define the capacities properly, their description of the task-solving process (in terms of its learning paths) can include errors. On the other hand, this result suggests the importance of having programs to prepare teachers to formulate and develop the capacities connected to a learning goal with the right precision.

The study also shows that some groups did not use the information they produced with the learning goal diagram to establish the extent to which the tasks contributed to this learning Bolema, Rio Claro (SP), v. 32, n. 61, p. 459-479, ago. 2018 
goal and to reformulate them, while the rest of the groups did. This was a requirement of the task. This result suggests that some groups did not develop the practical knowledge for this facet for the learning hypotheses notion.

The results show that the groups were also partially successful in developing the pedagogical concept knowledge, from the TTPK model perspective. We found some groups located on the weak or medium development level in the three knowledge types and others on the medium and advanced levels. This result raises two issues: (a) that it is possible to develop the three knowledge types for the pedagogical concept, and (b) that achieving this learning expectation is not automatic or simple.

The results of this paper show the usefulness of the TTPK model for studying teachers' learning and knowledge of pedagogical concepts. It allows the researcher to distinguish the kind of theoretical knowledge that a teacher can develop, from the technical knowledge necessary to use the theoretical knowledge for analyzing concrete mathematics topics and from the practical knowledge of using that information with pedagogical purposes. Teachers need to enact their practical knowledge in their teaching practice to contribute to their students' learning. But practical knowledge cannot be developed alone. It requires the information that emerges from enacting the technical knowledge on the topic, which in turn, involves putting their theoretical knowledge in practice. Therefore, this study confirms previous results on the way of developing the three knowledge types (GÓMEZ et al., 2008): Theoretical, technical, and practical knowledge of a pedagogical concept are developed simultaneously and interdependently in the course of the education program.

This paper shows that teaching and learning the pedagogical concept of learning hypothesis is not an easy process. In particular, teacher education programs should attend to the precision with which teachers define the capacities that characterize their students' performance and should motivate teachers to appreciate the usefulness of characterizing a learning goal with a diagram as a means for improving the tasks designed for promoting their students' learning.

\section{Acknowledgements}

This work was partially supported by projects EDU2012-33030 of the Spanish Ministry of Science and Technology and project FP44842-218 of Colciencias, Colombia.

\section{References}

ARISTOTLE. Nicomachean Ethics. Cambridge, MA: Harvard University Press. 350 BC/1994 
BACK, S. The Aristotelian challenge to teacher education. History of Intellectual Culture, v. 2, n. 1, p. 2-4. 2002.

BERNAL, M. L. et al. Método gráfico para resolver sistemas de ecuaciones lineales 2x2. In: GÓMEZ, P. (Ed.). Diseño, implementación y evaluación de unidades didácticas de matemáticas en MAD 1. Bogotá: Universidad de los Andes, 2014. p. 200-260.

CHARALAMBOUS, C. Y. Mathematical knowledge for teaching and the unfolding of tasks in mathematics lessons: Integrating two lines of research. In: FIGUERAS, O.; CORTINA, J. L., et al (Ed.). International Group for the Psychology of Mathematics Education. Morelia, México: PME, 2008. p. 281-288.

CHICK, H. L. Teaching and learning by example. In: WATSON, J.; BESWICK, K. (Ed.).Mathematics: Essential research, essential practice. (Proceedings of the 30th annual conference of the Mathematics Education Research Group of Australasia). Australia: MERGA, v. 1, 2007. p. 3-2.

CLARKE, D.; ROCHE, A. Teachers' extent of the use of particular task types in mathematics and choices behind that use. In SPARROW, L.; KISSANE, B.; HURST, C. (Eds.) Shaping the future of mathematics education: Proceedings of the 33rd annual conference of the Mathematics Education Research Group of Australasia. Fremantle: MERGA, 2010. p. 153-160.

CLEMENTS, D. H.; SARAMA, J. Learning trajectories in mathematics education. Mathematical Thinking and Learning, v. 6, n. 2, p. 81-89, 2004.

CLEMENTS, D. H.; et al. Mathematics learned by young children in an intervention based on learning trajectories: A large-scale cluster randomized trial. Journal for Research in Mathematics Education, v. 42, n. 2, p. 127-166, 2011.

COONEY, T. J. Pluralism and the teaching of mathematics. In: CLARKE B.; CLARKE, D. M., et al (Ed.). International perspectives on learning and teaching mathematics. Göteborg, Suecia: National Center for Mathematics Education, 2004. p. 503- 517.

CORCORAN, T.; MOSHER, F. A.; ROGAT, A. Learning progressions in science. Philadelphia, PA: Center for Continuous Instructional Improvements. Columbia University, New York: Teacher College Press. 2009. 86 p.

DARO, P.; MOSHER, F. A; CORCORAN, T. Learning trajectories in mathematics: a foundation for standards, curriculum, assessment, and instruction. Philadelphia, PA: Centre for Continuous Instructional Improvements. Columbia University, New York: Teacher College Press. 2011. 84 p.

GÓMEZ, P.; et al. Learning the notion of learning goal in an initial functional training program. In: FIGUERAS, O.; CORTINA, J. L., et al (Ed.). Joint Meeting of the International Group for the Psychology of Mathematics Education (IGPME 32) and North American Chapter (PME-NA XXX). Morelia: Cinvestav-UMSNH, v. 3, 2008. p. 81-88.

GÓMEZ, P.; GONZÁLEZ, M. J.; ROMERO, I. Caminos de aprendizaje y formación de profesores de matemáticas. In: RICO, L.; CAÑADAS, M. C., et al (Eds.). Investigación en Didáctica de la Matemática. Homenaje a Encarnación Castro. Granada: Comares, 2013. p. 177-183.

GÓMEZ, P.; GONZÁLEZ, M. J.; ROMERO, I. Caminos de aprendizaje en la formación de profesores de matemáticas: objetivos, tareas y evaluación. Profesorado. Revista de Curriculum y Formación de Profesorado, v. 18, n. 3, p. 319-338, 2014. 
GONZÁLEZ, M. J.; GÓMEZ, P. Conceptualizing and describing teachers' learning of pedagogical concepts. Australian Journal of Teacher Education, v. 39, n. 12, p. 13-30, 2014.

GRAVEMEIJER, K. Local instruction theories as means of support for teachers in reform mathematics education. Mathematical Thinking and Learning, v. 6, n. 2, p. 105-128, 2004.

LESH, R.; YOON, C. Evolving communities of mind - In which development involves several interacting and simultaneously developing strands. Mathematical Thinking and Learning, v. 6, n. 2, p. 205-226, 2004.

ORTON, R. E. Toward an Aristotelian model of teacher reasoning. Journal of Curriculum Studies, v. 29, n. 5, p. 569-584, 1997.

RINK, J. E. Teacher Education: A Focus on Action. Quest, v. 45, n. 3, p. 308-320, 1993.

SAUGSTAD, T. Aristotle's contribution to scholastic and non-scholastic learning theories. Pedagogy, Culture \& Society, v. 13, n. 3, p. 347-366, 2005.

SCHOENFELD, A. H. Models of the Teaching Process. Journal of Mathematical Behavior, v. 18, n. 3, p. 243-261, 2000.

SHULMAN, L. S. Those who understand: knowledge growth in teaching. Educational Researcher, v. 15, n. 2 , p. $4-14,1986$.

SIMON, M. A. Reconstructing mathematics pedagogy from a constructivist perspective. Journal For Research in Mathematics Education, v. 26, n. 2, p. 114-145, 1995.

SIMON, M. A. The challenge of mathematics teacher education in an era of mathematics education reform. In: JAWORSKI, B.; WOOD, T. (Ed.). The international handbook of mathematics teacher education. Rotterdam: Sense Publisers, v. 4, 2008. p. 17-29.

SIMON, M. A.; TZUR, R. Explicating the role of mathematical tasks in conceptual learning: an elaboration of the hypothetical learning trajectory. Mathematical Thinking and Learning, v. 6, n. 2, p. 91-104, 2004.

STEFFE, L. P. On the construction of learning trajectories of children: The case of conmensurable fractions. Mathematical Thinking and Learning, v. 6, n. 2, p. 129-162, 2004.

WILSON, P. H. Teachers' uses of a learning trajectory for equipartitioning. (Ph.D). North Carolina State University, North Carolina, 2009.

WILSON, P. H.; SZTAJN, P.; EDGINGTON, C. Designing professional learning tasks for mathematics learning trajectories. PNA, v. 7, n. 4, p. 133-141, 2013.

Submetido em 04 de Maio de 2017. Aprovado em 21 de Fevereiro de 2018. 